\title{
A Case Study of Safety Monitoring Program for Existing Bridge Crossing a Twin Tower Construction Project
}

\author{
Prateek Mehrotra \\ Rite Geosystems WLL \\ P.O. Box-30626 \\ Doha, Qatar
}

\author{
George Papastamos \\ Moniterra Group \\ Kennedy Str.72, 1076 \\ Nicosia, Cyprus
}

\author{
Ritvick Bhalla \\ Student \\ Vasant Valley School \\ New Delhi, India
}

\begin{abstract}
In the paper, the author presents a case study of instrumentation and monitoring (I\&M) program executed by a geotechnical instrumentation specialist organization during construction of twin high rise structures, in a megacity in Middle East. The project's work site was dissected by an existing busy road bridge. Two multi-storeyed towers with several basement levels each were to be constructed on both sides of the bridge. The towers were to be linked by a sky bridge. Safety of the existing busy road bridge located in the middle of the deep excavations during the construction stage was on top priority for all project stakeholders as well as the assets' owners.
\end{abstract}

The paper starts off with a brief overview of the project with salient features of the construction methodology deployed, followed by the description of instrumentation and monitoring scheme implemented for monitoring during construction works. Details of key parameters monitored and type of instruments selected for the purpose have also been included. The instrumentation and monitoring done for bridge monitoring has been described in detail which includes description of the setup of automated data collection for geotechnical and geodetic instruments, data transmission and its online presentation. Challenges faced during the installation of instruments in the bridge and around the deep excavations and how these were met with practical solutions are mentioned in the subsequent section.

Fast processing of the collected data, its lucid presentation for easy assimilation and its instant access-not restricted by geographical boundaries - is the key feature of a successful I\&M programme. This aspect is covered in the paper along with a summary of the observed data. Key conclusions drawn from the instrumentation programme and lessons learned, sum up the paper.

\section{Keywords}

Online monitoring, existing bridge monitoring, deep excavation monitoring, automatic data collection

\section{INTRODUCTION}

The project comprised of two towers-tower A and tower B on either side of an existing road bridge, which passed through the center of plot. Tower A with 66 levels, total height of 305 $\mathrm{m}$, was for mixed-use with residential, commercial spaces and hotel. Tower B was a $240 \mathrm{~m}$ tall structure with 56 levels comprising of residential apartments.

The Podium of towers had 3 levels and the basement comprised of 7 levels for car park. The excavation levels for construction of the basement ranged from 23.8 to $25 \mathrm{~m}$ below the existing ground level.

The two towers were linked together by a $225 \mathrm{~m}$ long sky bridge which cantilevered $70 \mathrm{~m}$ beyond tower A. Basements of the two towers were also connected with two tunnels located underneath the existing bridge. Excavation to a depth of $9 \mathrm{~m}$ below the existing ground level was required for the tunnels.

A comprehensive instrumentation and monitoring programme was planned by the designers for mitigating any risk of damage to the existing assets within and outside construction boundaries. This included the existing busy road bridge that crossed the construction site from the center.

\section{MONITORING REQUIREMENTS}

Monitoring requirements worked out by the project designers comprised of the following:

[1] Inclinometers and 3D optical targets on the shoring walls to monitor lateral and vertical deflections of shoring wall due to excavation.

[2] 3D optical targets on bridge piers and at mid-span to monitor the existing bridge movements in horizontal and vertical planes.

[3] Strain gages on the bridge segments above the piers and at mid-span to monitor the stresses developing in the bridge due to excavation and dewatering works.

[4] Temperatures were monitored on top, bottom and sides of bridge deck to correlate the monitoring data with ambient temperature changes.

[5] Groundwater was monitored within the construction area in dewatering wells and outside excavation area with standpipe piezometers.

Refer to Figure 1 for instrumentation layout plan of the project. In the following sections, a detailed description of monitoring program for the most critical structure of project i.e. the existing busy road bridge using 3D targets, strain gages and temperature sensors is given. 


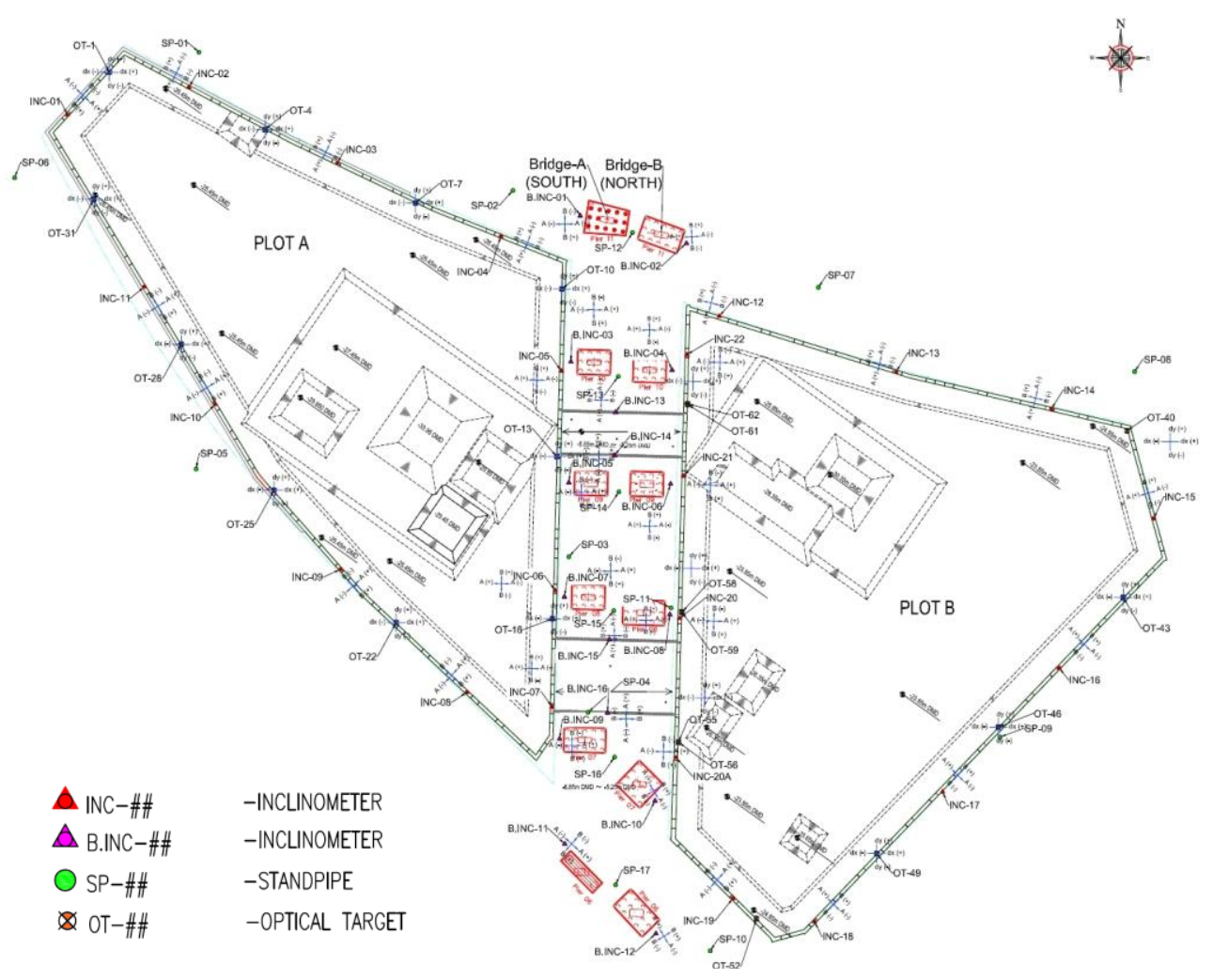

Figure 1: Instrumentation layout plan

\section{AUTOMATIC 3D DEFORMATION MONITORING SYSTEM FOR BRIDGE}

The automatic 3D deformation monitoring system used for measurements of the bridge piers comprised of automatic total stations (ATS) controlled by dedicated control boxes (see Figure 2) and a monitoring database management software installed on a central server.

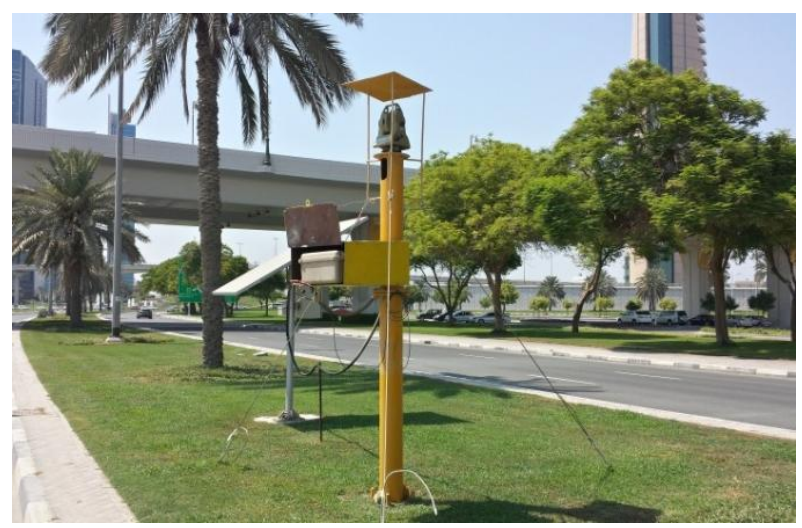

Figure 2: Installed ATS on site with control box and solar panel power supply

The control box included a preprogrammed software that controlled the ATS and scheduled the frequency of measurements, filters of acceptance or repetition of each measurement, calculation and repositioning of the total station etc.

Figure 3 gives the locations of 3 no. automatic total station used in the project.

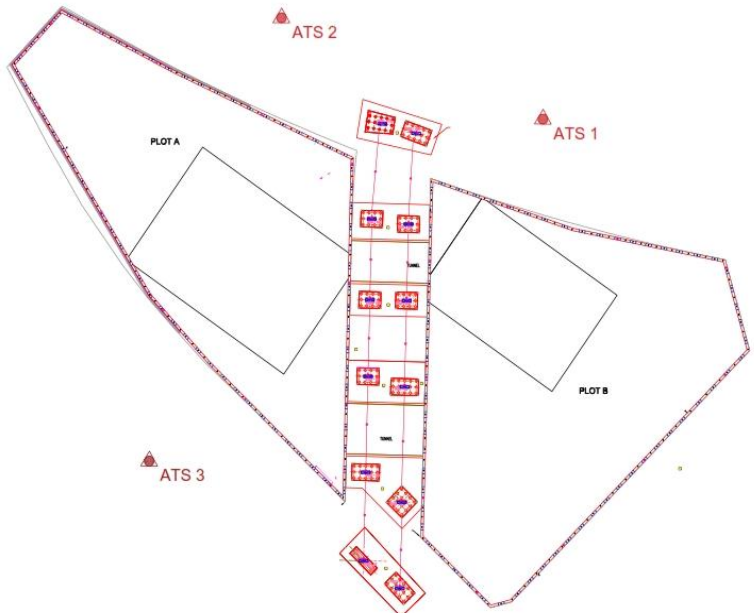

Figure 3: Sketch of the location of the ATS

These ATS measured prism targets installed on both sides of the piers and at mid-span on each bridge. Each ATS had dedicated number of prism targets for measurements. The frequency of automatic measurement was programmed at 20 minutes.

Figure 4 shows location of prism targets on each of the 12 no. bridge piers monitored. Targets were also installed at the midspans of the bridge. After completion of each monitoring cycle at a frequency of 20 minutes, the raw data was transmitted to central server with database management software, using cellular network. The database management software processed the data and results were displayed in tabular and graphical formats. 


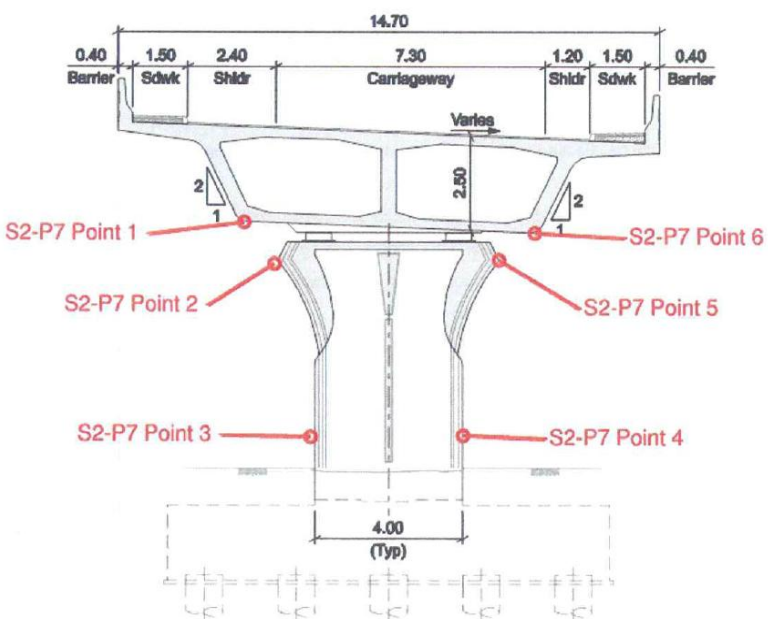

Figure 4: Configuration of the optical targets

The above mentioned system ensured timely monitoring of displacements, simultaneous wireless transmission of the results and entry into the database management system to ensure minimal time between taking measurements and data evaluation.

\subsection{Geodetic Network Setup}

A network of reference prisms was established around the site in order to provide orientation to the ATSs. The positions of the reference points were chosen considering the following:

- All of the reference points are located outside the construction area i.e. zone of influence

- The reference points are shared between the ATSs.

The reference prisms were positioned on small concrete pillars specifically constructed for the project and also on the existing structures located outside the zone of influence of the construction.

\subsection{Automatic Total Station (ATS)}

Each ATS was positioned on a 3 metallic pillar specially fabricated for the project (see Figure 4). These were installed outside the influence zone as far as possible, still not too far away from the bridge elements which need to be monitored. Positions of the ATS were determined after site inspections in such manner that a clear visibility was obtained for all installed monitoring prisms and reference prisms. Also it was seen that the location had minimal vibration from the construction activities.

\subsection{Installation of Optical Targets}

Monitoring prisms were installed on each of the 12 piers of the bridge as well as the midspan between piers according to the visibility from the ATS locations and surrounding activities (see Figure 4). This setup ensured that the bridge was monitored from both sides.

\subsection{Measurements, Processing \& Reporting}

The process implemented can be described as Automatic Monitoring System with Human Interface for Evaluating Data
(AMS-HIED). Workflow of the entire process is performed in following steps:

\subsubsection{Upload of Measurements to the Monitoring}

Database

After upload of the raw measurements in the database from each 20 minute cycle, the software automatically applied the following filters in order to minimize the noise:

3.4.1.1 Applying the Filter for Random Error Cap Random error is an error which comes accidentally as an unpredicted event and effects the measurement in a way that amplifies the results in very large scale. Examples of the random errors are disturbance in the line of sight causing the laser beam from the ATS to travel longer time than in normal case and as a result to produce the bigger distance and consequently wrong coordinates of the optical target; reflections from the mirrors of the moving vehicles; physical influence to the monitoring post etc.

Random error cap was incorporated into the system with the purpose of automatic recognition and deactivation of those values which are affected by this error. This cap stops the unrealistic high values (which are beyond any possible movement) which could create a false alarm from entering into the alert system. The readings still remained in the monitoring database.

Applying the cap for random error was done automatically (automatic recognition and deactivation) on all collected data. All values falling outside the predefined cap e.g. $\mathrm{R}=+/-2.5$ $\mathrm{cm}$. were deactivated by the administrator. The cap value was subject to re-evaluation in case of real settlement of this magnitude occurre1qd.

\subsubsection{Applying Moving Average Filter}

The moving average filter reduces random noise while retaining a sharp step response. Figure 5 shows an example of how it works.

The measurements in (a) have been weighed down with random noise. In (b) and (c), the smoothing action of the moving average filter decreases the amplitude of the random noise and also reduces the sharpness of the edges. Of all the possible linear filters that could be used, the moving average produces the lowest noise for a given edge sharpness.

Given a series of numbers and a fixed subset size, the first element of the moving average is obtained by taking the average of the initially fixed subset of the number series. Then the subset is modified by "shifting forward"; that is, excluding the first number of the series and including the next number following the original subset in the series. This creates a new subset of numbers, which is averaged. This process is repeated over the entire data series. The plotline connecting all the (fixed) averages is the moving average. A moving average is a set of numbers, each of which is the average of the corresponding subset of a larger set of datum points. 

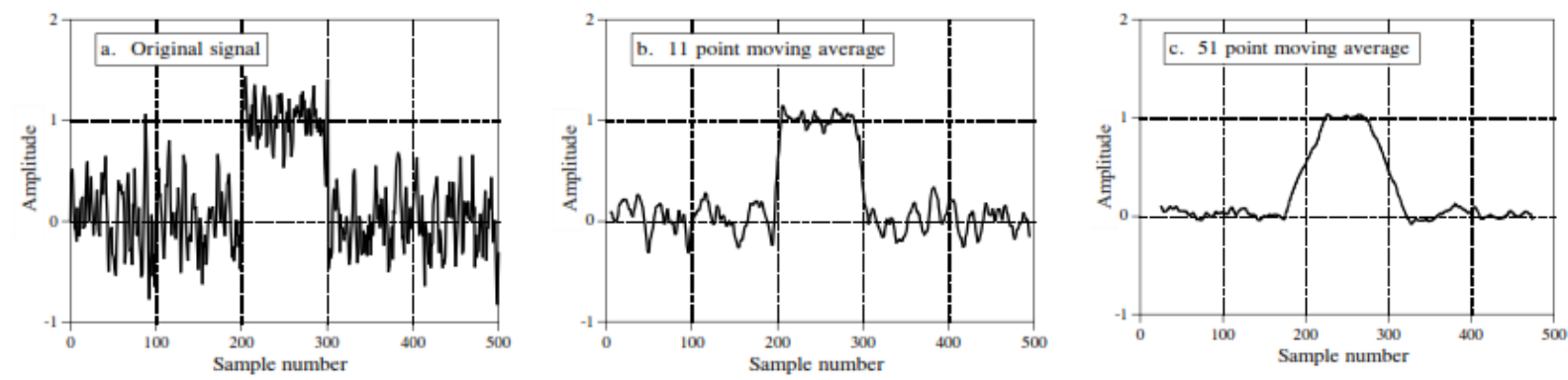

Figure 5: Moving average filter

For the project described in the paper, the moving average filter was determined on the basis of number of measurements in one day. Same factor was applied to the each of the 3 values, DHTX (lateral movement along the bridge alignment), DDCL (lateral movement perpendicular to the bridge alignment) and DZ (vertical displacement). Values calculated using the moving average filter were used for representing the curves of the trend lines.

\subsubsection{Automatic Input to Tony Gee report}

An Excel spreadsheet was developed by bridge designer-Tony Gee, in which differential settlements and lateral movement of the bridge were taken into account. Pier movements were checked against the actual design capacity of the bridge deck section. A modification to original database software was applied in order to:

- Automatically input the results in the spreadsheet

- Automatic reading of the results and automatic notification in case of alarm (SMS and emails)

- Upload

- the report to web cloud under the 20 minutes reporting regime

Automatic preparation of the data for input into the spreadsheet (averaging the values of prisms on the same level from both sides of the piers) was done by the database software. For each pier, 4 prisms were taken into account for the analysis. Two prisms on the top of the pier, two prisms on the bottom of the pier (see Figure 6) as described below:

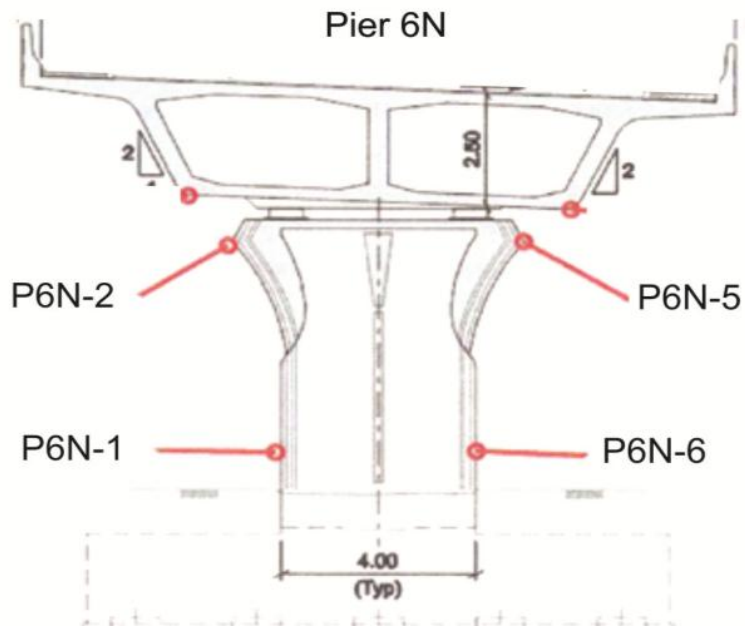

Figure 6: Schematic view of the used prisms for Tony Gee spreadsheet a. From two prisms on top of the pier (prism P6N-2 and prism $\mathrm{P} 6 \mathrm{~N}-5$ ), the software averaged the readings representing the lateral movement to the bridge (DDCL) and stored it in the correspondent cell for TOP SURVEY POINT VALUES AVERAGE (see Figure )

b. From the two prisms on bottom of pier (prism P6N-1 and prism P6N-6), the software again averaged the readings for lateral movement to the bridge (DDCL) and stored it in the correspondent cell for BOTTOM SURVEY POINT VALUES AVERAGE (see Figure 7).

c. From two prisms on bottom of the pier (prism P6N-1 and prism P6N-6), the software averaged the readings for vertical movement (DZ) also and stored it in the correspondent cell for VERTICAL DISPLACEMENT AVERAGE (see Figure 7).

The system automatically compared the results imputed into the Tony Gee spreadsheet to trigger values and provided the following alarms states (see Figure 8):

- GREEN STATE: System confirmed that results are "OK"; the report was generated and uploaded to the web cloud.

- ORANGE STATE: System confirmed "Action" or "Overloaded" condition; the alarm were sent to all parties according to the communication protocol.

In case the ORANGE STATE occurred, Monitoring Engineer took following actions to re-confirm readings for the affected $\operatorname{prism}(\mathrm{s})$ :

- Reconfigure ATS for affected pier to ensure that all affected optical targets were monitored within the 20 minutes span. This allowed the system to have multiple readings which were used for confirmation of the results from the Tony Gee spreadsheet

- Manual crosscheck of the values: Manual crosscheck of the settlement was performed for verification of the readings from the ATS. Settlement was measured on the installed settlement markers on the opposite side of each pier and compared with the baseline values taken previously

- Evaluation of the manual crosscheck data: The Monitoring Engineer evaluated data from the manual crosscheck and repeated the spreadsheet input with the newly acquired data from the ATS:

- Case 1: If it turned out to be "OK" state then GREEN STATE of alarm was announced and the subsequent process continued i.e. report was generated and sent to all concerned parties. For the false alarm, an incident report was included in the weekly report. 


\begin{tabular}{|c|c|c|c|c|c|c|c|c|c|c|}
\hline & & & \multicolumn{5}{|c|}{ Survey Point Record Sheet } & $\begin{array}{l}\text { Name of } \\
\text { Surveyor: }\end{array}$ & & \\
\hline & & \multicolumn{6}{|c|}{ Bridges N2 and N3 } & Date: & & \\
\hline \multicolumn{11}{|c|}{ SURVEY INPUTS } \\
\hline \multicolumn{11}{|c|}{ Top Survey Point Values average- LATERAL } \\
\hline $\mathrm{P} 6$ & P7 & P8 & P9a & P9b & P10 & P11 & P12 & P13 & P14 & \multirow{3}{*}{$\mathrm{mm}$} \\
\hline-0.3 & -0.7 & 0.5 & 0.5 & 0.5 & -0.9 & -0.3 & 0 & 0 & 0 & \\
\hline \multicolumn{10}{|c|}{ Average value of prisms $\mathrm{P} 6 \mathrm{~N}-2$ and $\mathrm{P} 6 \mathrm{~N}-5$ for lateral movement to bridge } & \\
\hline \multicolumn{10}{|c|}{ Bottom Survey Point Values average- LATERAL } & \multirow{4}{*}{$\mathrm{mm}$} \\
\hline PG & P7 & P8 & P9a & $\mathrm{P} 9 \mathrm{~b}$ & P10 & P11 & P12 & P13 & P14 & \\
\hline 0.1 & -0.2 & -1.5 & 0.7 & 0.7 & -0.2 & -0.1 & 0 & 0 & 0 & \\
\hline \multicolumn{10}{|c|}{ Average value of prisms $\mathrm{P} 6 \mathrm{~N}-1$ and $\mathrm{P} 6 \mathrm{~N}-6$ for lateral movement to bridge } & \\
\hline \multicolumn{10}{|c|}{ Vertical displacement average } & \multirow{4}{*}{$\mathrm{mm}$} \\
\hline P6 & P7 & P8 & P9a & P9b & P10 & P11 & P12 & P13 & P14 & \\
\hline-0.6 & 0.3 & 0.0 & -0.6 & -0.6 & 0.3 & 0.9 & 0 & 0 & 0 & \\
\hline \multicolumn{10}{|c|}{ Average value of prisms $\mathrm{P} 6 \mathrm{~N}-1$ and $\mathrm{P} 6 \mathrm{~N}-6$ for vertical movement bridge } & \\
\hline
\end{tabular}

Figure 7: Tony Gee spreadsheet and input of values

RESULTS

\begin{tabular}{|c|c|c|c|c|c|c|c|c|c|}
\hline \multicolumn{9}{|c|}{ Lateral Bearing Capacity Result } \\
\hline P6 & P7 & P8 & P9d & P90 & P10 & P11 & P12 & P13 & P14 \\
\hline OK & OK & OK & OK & OK & OK & OK & OK & OK & OK \\
\hline
\end{tabular}

\begin{tabular}{|c|c|c|c|c|c|c|c|c|c|}
\hline \multicolumn{9}{|c|}{ Vertical Bearing Capacity Result } \\
\hline P6 & P7 & PO & P9d & P9o & P10 & P11 & $P_{12}$ & P13 & P14 \\
\hline OK & OK & OK & OK & OK & OK & OK & OK & OK & OK \\
\hline
\end{tabular}

\begin{tabular}{|c|c|c|c|c|c|c|c|c|}
\hline \multicolumn{9}{|c|}{ Pier Rotation Check } \\
\hline P6 & P7 & P8 & P9 & PIO & P11 & P12 & P13 & P14 \\
\hline OK & OK & OK & OK & OK & OK & OK & OK & OK \\
\hline
\end{tabular}

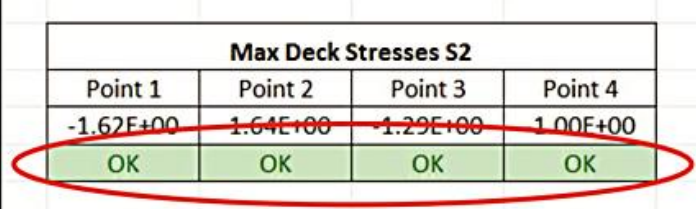

\begin{tabular}{|c|c|c|c|}
\hline \multicolumn{4}{|c|}{ Max Deck Stresses S3 } \\
\hline Point 1 & Point 2 & Point 3 & Point 4 \\
\hline$-5.20 E-01$ & $1.71 E=01$ & $-2.55[+00$ & $252 \mathrm{~F}+00$ \\
\hline OK & OK & OK & OK \\
\hline
\end{tabular}

\section{Figure 8: Alert status from the Tony Gee spreadsheet results}

- Case 2: In case of confirmation of the ORANGE STATE values, the system automatically sent an alarm notification to everybody in the action list.

\section{STRAIN \& TEMPERATURE}

\section{MEASUREMENTS FOR THE BRIDGE}

Vibrating wire type strain gages were used to measure the change in strain of bridge's structure owing to construction activities. Change in stress was obtained by multiplying the measured change in strain by modulus of elasticity of concrete.

The strain gages were installed at 10 sections of the bridge and at each section one strain gage was installed at roof, one at base and one each at side walls. Figure 9 below shows the location of strain gages (SG) along with thermistor type temperature sensors $(\mathrm{TH})$ at one of the bridge sections.

In total 40 no. of strain gages and 48 no. temperature sensors were installed on the bridge. The data from the strain gages and temperature sensors was logged automatically every 15 minutes per day. The data was transmitted over the cellular network to a central server. The data was processed and hosted on the website created for this project. Username and password for the website was made available to all stakeholders of the project.

The initial reading of the installed strain gages was taken as zero and changes have been monitored since then. Change with '+' sign indicated tensile strain and that with '-'sign indicated compressive strain. 
The general trend of strain gage data indicated a cyclic change with strain increasing to a maximum in the peak summer months and decrease winters approached.

\subsection{Temperature Correction Applied to the Strain Gage Data}

Temperature variations during the day and over the year in various seasons, the effect of solar radiations during the day, variations in traffic load, creep and wind effects results in a change in stress in the structure of the bridge. This affected the readings of the strain gages installed in the bridge. Refer to graphs of one of the strain gages SG-1 installed in the bridge given in (see Figure 10).

The strain gage showed a temperature variation of $4.4^{\circ} \mathrm{C}$ during the period of November 13 to November 27, 2016. During this period the change in strain reading was 10 micro- strain. For online display of the strain reading, a correction of 10 microstrains per $4.4^{\circ} \mathrm{C}$ was made. Refer to Figure 11 for the graph of temperature-corrected data of strain gage.

The same procedure was followed for correcting the data of all strain gages mounted in the bridge.

For analysis purpose it is to be noted that strain gages did not measure the actual strain/stress in the structure; these measured only the values of change in strain/stress from the date of their installation. The structure of the bridge is already stressed in compression at some locations and in tension in others. This change in strain/stress is, therefore, an addition/subtraction of the strain/stress existing in the structure at the time strain gages were installed.

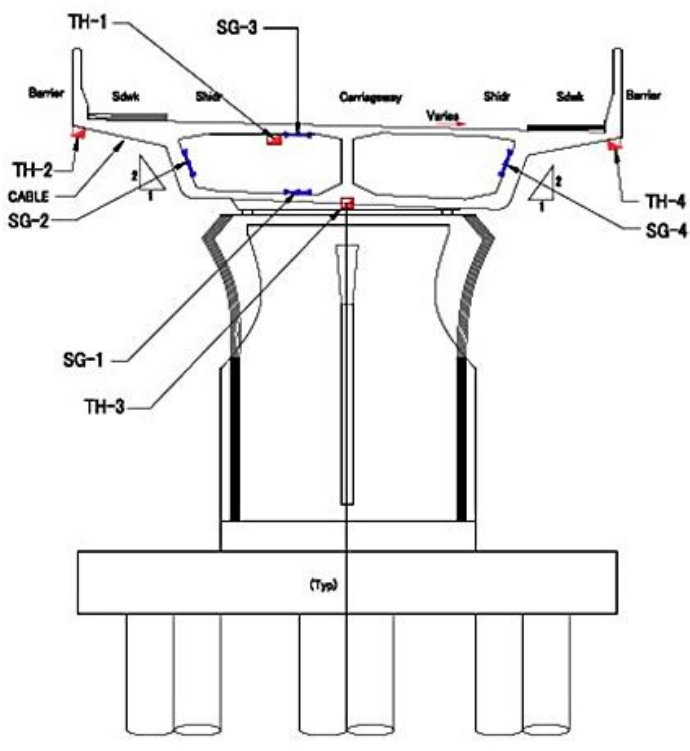

PIER-1; BRIDGE-A

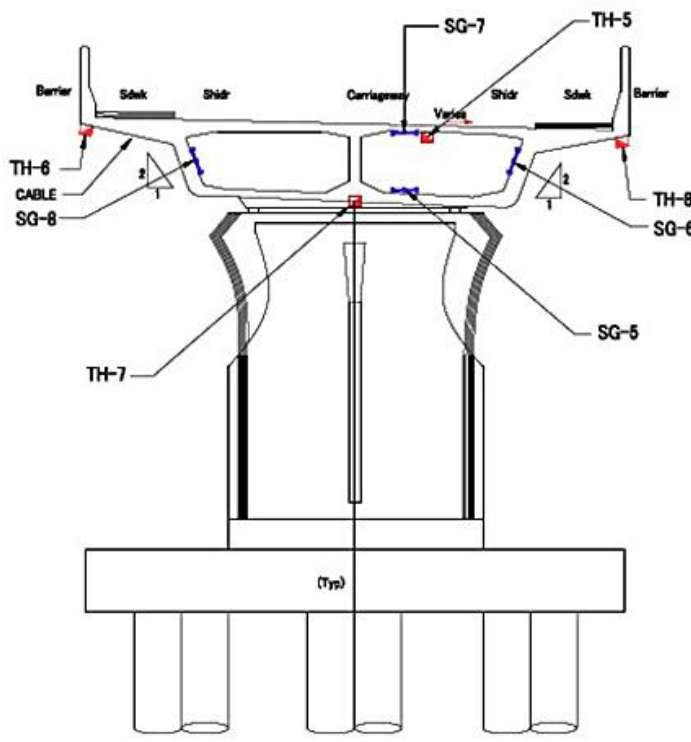

PIER-1; BRIDGE-B

Figure 9: Strain gage and temperature sensor layout plan

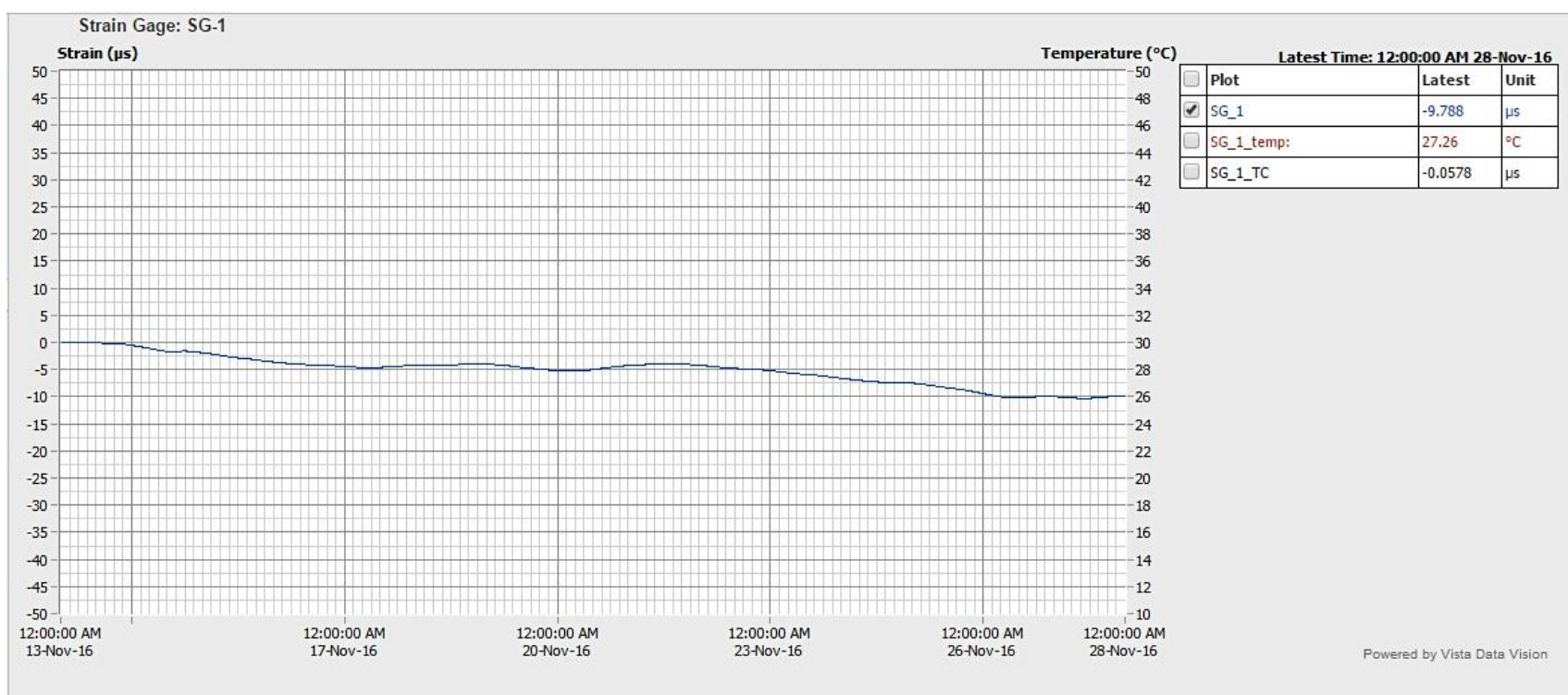




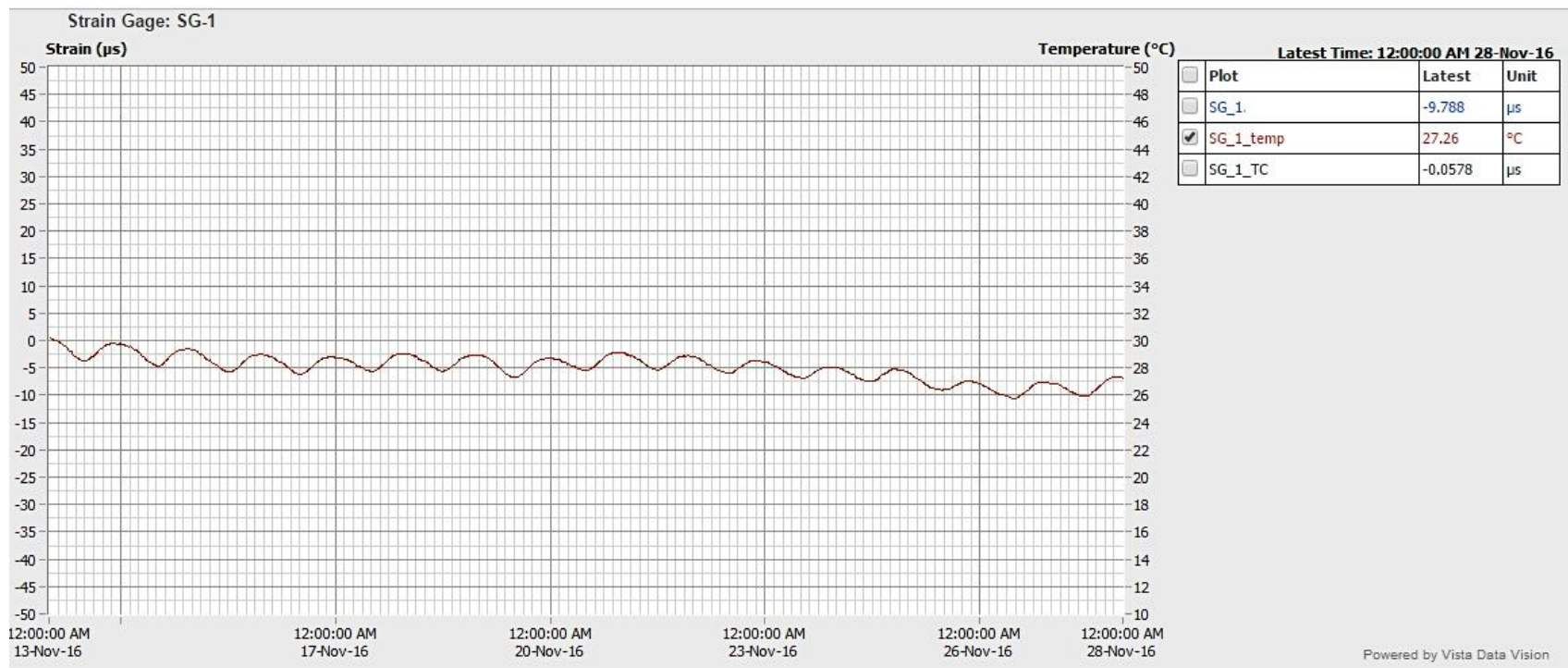

Figure 10: Strain (above) and temperature (below) graphs of strain gage SG-1

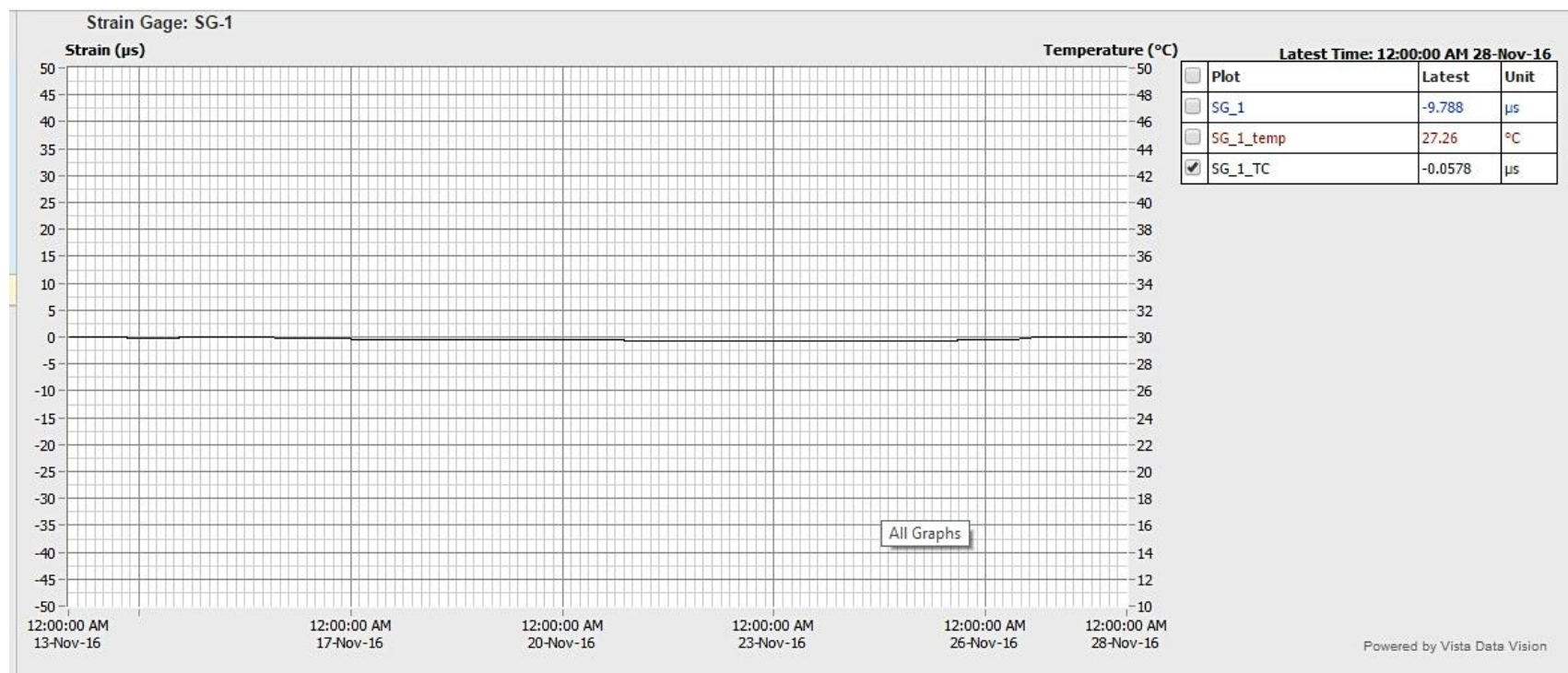

Figure 11: Temperature corrected graph of longitudinally installed strain gage SG-1

\section{DATA PRESENTATION}

For 3D deformation measurements, reporting of the Tony Gee spreadsheet comprising of differential settlements and lateral movement of the bridge and its comparison with the designed values was done every 20 minutes. The sheets were stored on the cloud and username and password was distributed to all stakeholders.

Weekly monitoring report with graphical data presentation for all instruments installed in the project including the ones manually monitored in the project i.e. inclinometers and standpipe piezometers. Examples of 3D deformation graphical data are given in Figure 12 where the horizontal axis is timescale in dates and a vertical scale is measured value in $\mathrm{mm}$. Graphs of the previous week data, as well as graphs of the historical data, were included. It also comprised of site progress pictures, instrumentation layout drawings and daily and incidence reports, if any, submitted during the previous week. As a summary of the day, daily monitoring reports of $3 \mathrm{D}$ deformation data using the values from 7 AM to 7 PM from the automatic monitoring were submitted.

\section{CHALLENGES FACED}

- Vibrating wire strain gages and temperature sensors were installed inside the bridge deck in confined spaces. No artificial sources of lighting were used only natural light coming from the service openings, which was just sufficient, was used during the work.

- Damages and obstructions to shoring instruments due to ongoing site construction activities.

- Power outages for the datalogger for strain gage and temperature sensors were encountered resulting in a few incidences of missed data. Diesel generator sets located at the site was the main source of power for the datalogger. Sudden power surges were also encountered. Subsequently, for powering up the monitoring system the generator sets were replaced with solar power systems with 3 days autonomy. An autonomy of 3 days was selected in view of mist encountered during the winters to ensure unhindered data collection and transmission during the critical stages of construction. 
- Access to the bridge decks for installation and maintenance purposes depended on the availability of man-lift from the main contractor. Hence it had to be planned in advance.

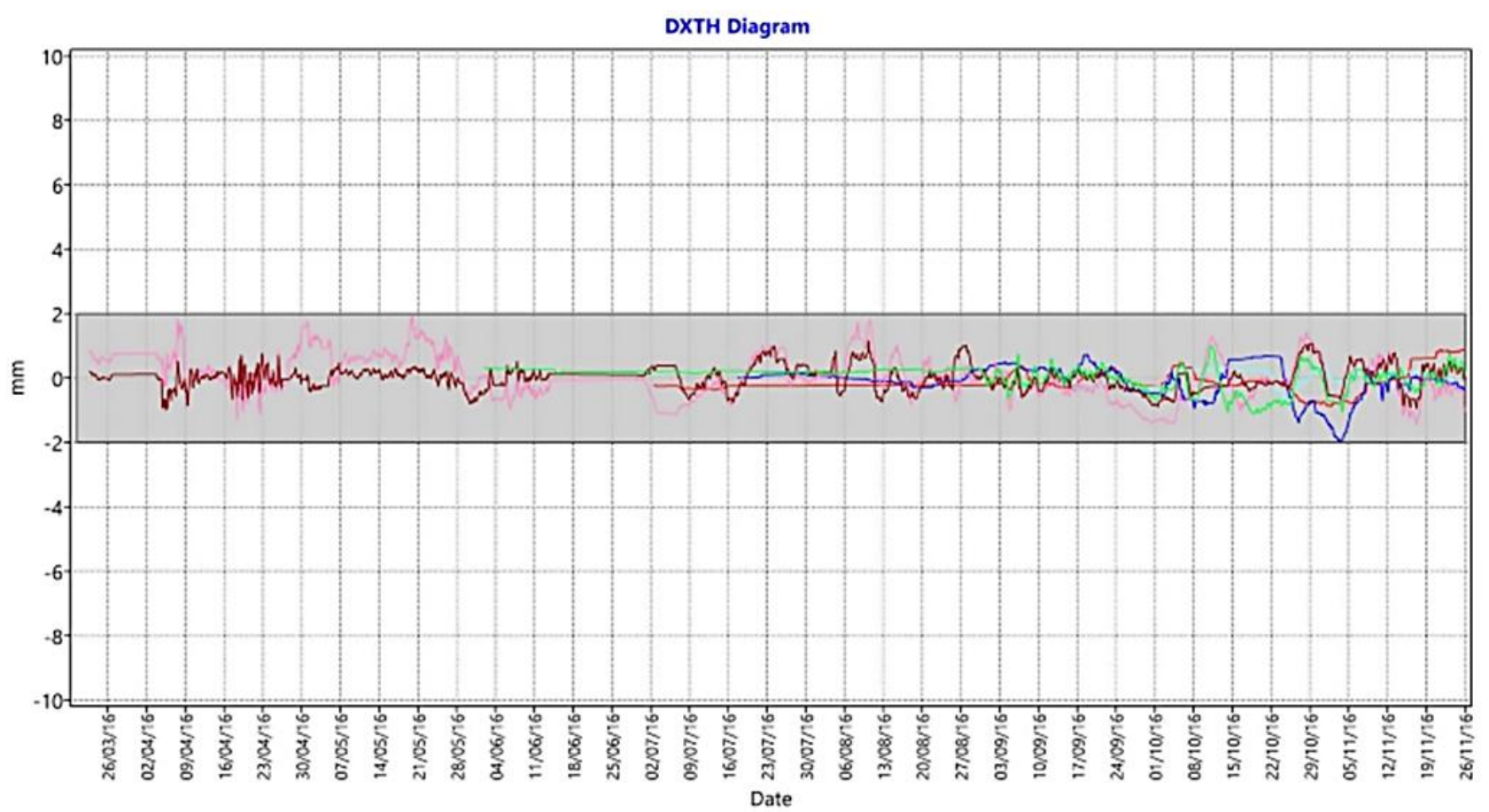

DDCL Diagram

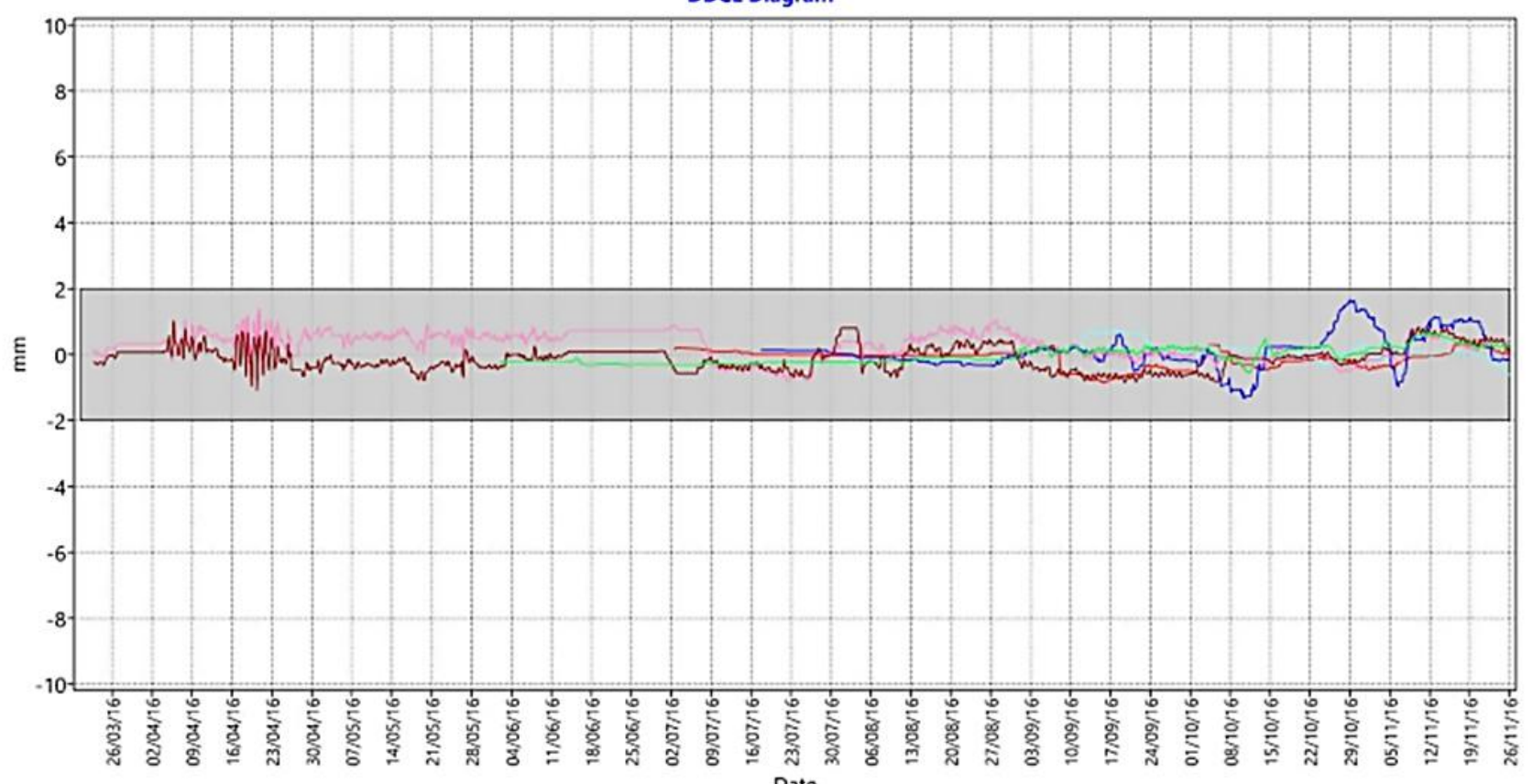
Date

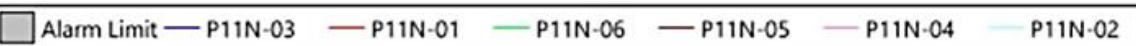




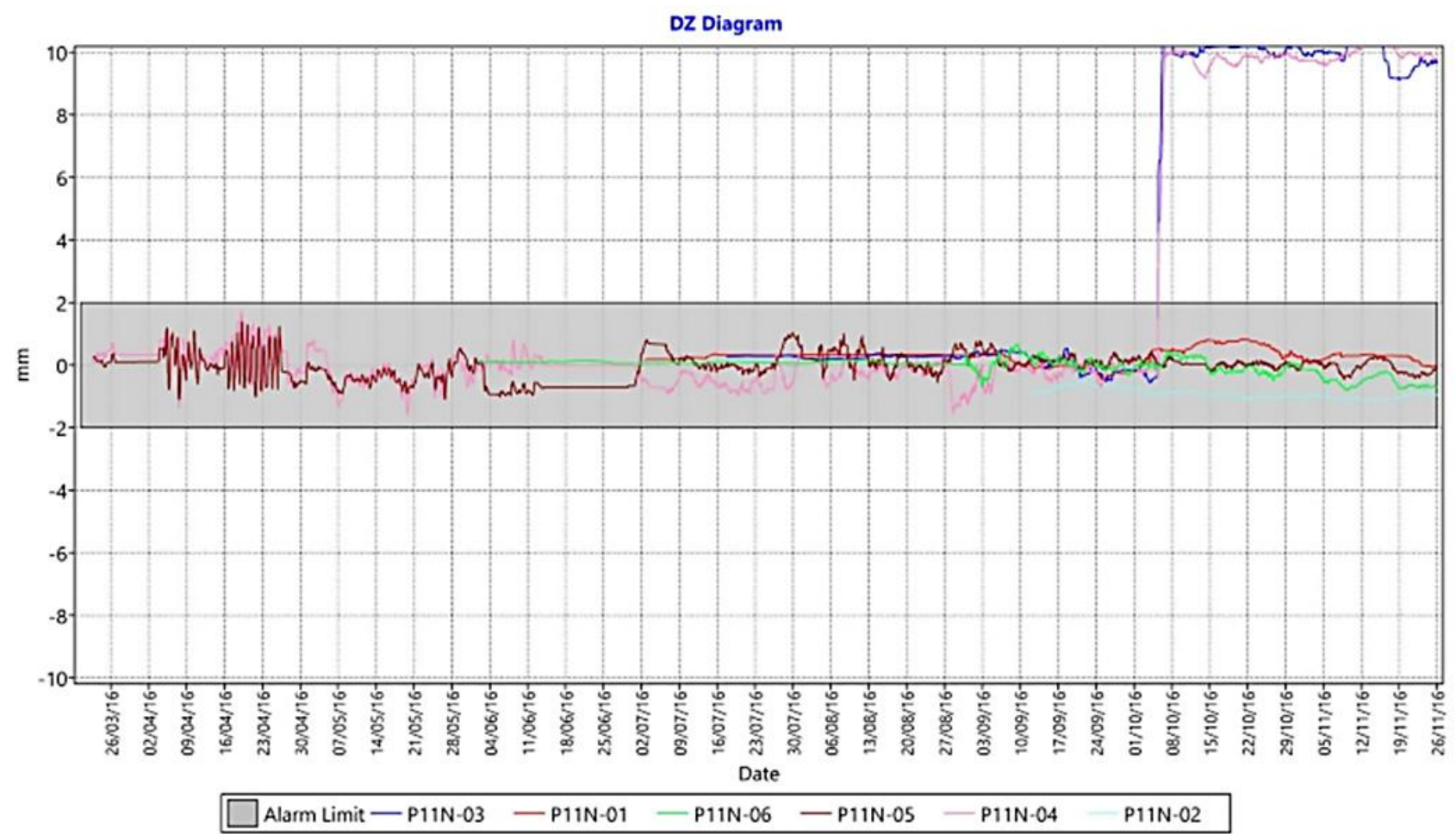

Figure 12: Example of the graph for longitudinal (top), lateral (middle) and vertical movements (bottom)

\section{CROSS-CHECKING OF 3D DEFORMATION DATA}

As per the directives of the main contractor, the bridge was jacked up at the mid-span to achieve a vertically upwards displacement of $10 \mathrm{~mm}$. Readings of 3D prism automatically collected by the ATS showed a movement close to the above value (see Figure 12). The exercise proved the sound functioning of the measurement system implemented.

\section{CONCLUSION}

The instrumentation and monitoring system implemented at a critical construction site located at heart of metropolis, helped in reducing risks, protecting existing assets and giving confidence to the construction process. Monitoring data was made available to all stakeholders seamlessly almost in the real time. This was possible with a combination of rugged sensors, advanced data collection and telemetry using the GSM network and web-based data monitoring service. Looking at the behaviour of strain readings caused by daily and seasonal temperature changes, it is highly recommended to have a minimum of 1 year of baseline data covering all seasons. This will go a long way in filtering temperaturerelated changes and determining those caused by the construction activities. Perseverance of the installation and monitoring personnel is also vital for successful execution such complex projects.

\section{REFERENCES}

[1] Dunnicliff, J. 1993. Geotechnical Instrumentation for Monitoring Field Performance. John Wiley and Sons, New York, NY, USA. 577p

[2] Users' manual of Model EDS-20V-AW vibrating wire weldable Strain Gage. Doc no. WI 6002.34. 2008. Encardio-rite Electronics Pvt. Ltd., Lucknow, UP - 226 011, INDIA. $27 \mathrm{p}$

[3] Juneau, F., Quirion, M. and Marcil L. 2001. Application note on Thermal Effects on Strain Measurement with Vibrating Wire or Fibre-Optic Strain Gage. Roctest Ltd. Quebec J4P 2P4 Canada. 4p

[4] Hashash, Y.M.A. Et al. 2003. Temperature Correction and Strut Loads in Central Artery Excavations. Journal Of Geotechnical And Geoenvironmental Engineering, Vol. 129, No. 6 @ ASCE. p495-505

[5] Papastamos, G. Et.al. 2014. 3-D strong tilting observed in tall, isolated brick chimneys during the excavation of the Athens Metro. Applied Geomatics (https://www.researchgate.net/publication/265298141) 